\title{
Prevalence of childhood Cancer among children attending referral hospitals of outpatient Department in Ethiopia
}

\author{
Aklilu Endalamaw', Nega Tezera Assimamaw², Tadesse Awoke Ayele ${ }^{3}$, Achenef Asmamaw Muche ${ }^{3}$, \\ Ejigu Gebeye Zeleke ${ }^{3}$, Amare Wondim², Getaneh Mulualem Belay ${ }^{2}$, Yeneabat Birhanu ${ }^{4}$, Ashenafi Tazebew ${ }^{5}$, \\ Masresha Asmare Techane ${ }^{2}$, Selam Fisha Kassa ${ }^{2}$ and Chalachew Adugna Wubneh ${ }^{2^{*}}$
}

\begin{abstract}
Introduction: Childhood cancer is one of the leading causes of morbidity and mortality in the pediatrics age group. The problem affects both developed and developing countries. A high mortality rate has been observed in low-income counties. Despite its high fatality rate, less attention has been paid to the problem in developing countries, including Ethiopia. For this reason, childhood cancer is not well documented in the study setting. Therefore, we assessed the prevalence of childhood cancer in Ethiopia.
\end{abstract}

Methods: Institution based cross-sectional study design from January 1, 2019, to March 30, 2019, was conducted in the pediatrics treatment center. A systematic random sampling technique has used to select 1270 children in the pediatric outpatient department. The data were entered using Epi info version 7 and exported to SPSS version 20 for analysis. We checked model fitness for the advanced statistical methods, but it was difficult to proceed with logistic regression model to see the association between dependent and explanatory variables because of the unmet $\mathrm{x}^{2}$ assumption. We presented the results by using tables and figures.

Results: From the total 1270 study participants, 1257 were included in the final analysis provided that a $98.97 \%$ response rate. Out of these, $10(0.8 \%)$ children were diagnosed with cancer. Regarding its types, two each, Acute Lymphocytic Leukemia, Wilms tumor, Hodgkin lymphoma, and one each non-Hodgkin lymphoma, Parotid cancer, Retinoblastoma, and Breast cancer were reported. The prevalence of childhood cancer was 0.9 and $0.7 \%$ among male and female children, respectively.

Conclusions: Eight children diagnosed with cancer per 1000 children who visited the pediatric outpatient department. Even though childhood cancers have little attention from policymakers, the prevalence of childhood cancer remains prevalent. Therefore, researchers and policymakers shall give special emphasis to childhood cancer.

Keywords: Cancer, Children, Ethiopia

\footnotetext{
* Correspondence: mekidem21@gmail.com

${ }^{2}$ Department of Pediatrics and Child Health Nursing, School of Nursing, College of Medicine and Health Sciences, University of Gondar, P.O.BOX 196, Gondar, Ethiopia

Full list of author information is available at the end of the article
}

(c) The Author(s). 2021 Open Access This article is licensed under a Creative Commons Attribution 4.0 International License, which permits use, sharing, adaptation, distribution and reproduction in any medium or format, as long as you give appropriate credit to the original author(s) and the source, provide a link to the Creative Commons licence, and indicate if changes were made. The images or other third party material in this article are included in the article's Creative Commons licence, unless indicated otherwise in a credit line to the material. If material is not included in the article's Creative Commons licence and your intended use is not permitted by statutory regulation or exceeds the permitted use, you will need to obtain permission directly from the copyright holder. To view a copy of this licence, visit http://creativecommons.org/licenses/by/4.0/ The Creative Commons Public Domain Dedication waiver (http://creativecommons.org/publicdomain/zero/1.0/) applies to the data made available in this article, unless otherwise stated in a credit line to the data. 


\section{Introduction}

Cancer is a collective term that refers to the body's uncontrolled abnormal cell growth and reproduction. This abnormal cell could destroy healthy tissue and then, spread beyond its usual boundaries [1]. Non-communicable diseases (NCD) including cancer considered as the disease of "adult only" in a sense children do not get cancer and childhood cancer not cured, which is a noticeable common false perception of the community but it is a preventable cause of morbidity, disability, and mortality [2-4]. Over $90 \%$ of childhood cancer deaths occur in low-resource settings because many children in low-and middle-income countries do not receive or complete care [5].

The burden of childhood cancer has been reported both in developed and developing countries. According to 2015 World Health Organization (WHO) report each year, more than 200,000 children are diagnosed with cancer globally. It is projected that an estimated 21 million people will be diagnosed by 2030 [6, 7]. It is estimated that 80 $85 \%$ of pediatric cancer cases occur in the developing world but $10 \%$ of them have survived [8]. In the USA, it is reported that there are an estimated 15,780 children between the ages of birth and 19 years of age who are diagnosed with cancer. Approximately 1 in 285 children diagnosed with cancer before their 20th birthday in the USA [9] and 174 cases per million children per year in Australia [10]. In Yemen, the incidence of childhood cancer is 1.9 per 100,000 and this disease was more common in different age groups of 5-9 years (35\%), 10-14 years (33.7\%), and 0-4 years (31\%) [11]. Similarly, cancer is an increasing public health burden for Ethiopia and SubSaharan Africa at large [12]. According to hospital records published in 2015 in Ethiopia, there are more than 150, 000 cancer cases per year approximately 6000 new cases of pediatric cancer each year [13]. Different strategies have been implemented to prevent specific cancer-causing agents. Notably, cancer caused by the human papillomavirus and hepatitis $B$ virus can be prevented through vaccination [14]. Furthermore, children who were exposed to radiation, like atomic bomb blast had a risk of leukemia, thyroid cancer risk due to a nuclear power plant, ultrasound, and computed tomography scan exposure during early pregnancy time. Family history of cancer, smoking history of the family, passive smoking exposure during pregnancy, white phosphorous, an overdose of radiation are some of the risk factors related to pediatric cancer [15-19]. On the other hand, inherent risk factors including birth weight, parental age, and congenital anomalies are consistently associated with most types of pediatric cancer which make challenging for pediatric cancer [20].

The extent of the cancer burden in the young population is unknown in many low-and middle-income countries. Even in the presence of population-based cancer registries, the collection of information about childhood cancers is often neglected and the least prioritized health issue similarly in Ethiopia.

Therefore, this study aimed to determine the prevalence of childhood cancer in Ethiopia. Hence, this study can be used as baseline data for health policymakers which help to design strategy in the country, childhood cancer researchers, and clinicians.

\section{Methods and materials}

\section{Study design and period}

An institution-based cross-sectional study design was conducted from January 1, 2019, to March 30, 2019.

\section{Study setting}

The study was conducted at the University of Gondar Comprehensive Specialized Hospital, Gondar and Felege Hiwot Referral Hospital, Bahir Dar Ethiopia. Gondar city is about $750 \mathrm{~km}(\mathrm{~km})$ far from the Northwest of Addis Ababa, the capital city of Ethiopia. Felege Hiwot referral hospital is found in Bahir Dar which is the city of Amhara region which is found around $321 \mathrm{~km}$ far from Addis Ababa. Both hospitals are serving more than 5 million people in their catchment areas.

\section{Source and study population}

All children who attended the pediatrics outpatient department (OPD) in the University of Gondar Comprehensive Specialized Hospital and Felege Hiwot Referral Hospital were the source population. All children who visited the pediatrics' OPD during the study period were considered as the study population.

\section{Sample size and sampling technique}

The sample size was determined by using a single population proportion formula with the statistical assumptions of $95 \%$ Confidence Interval (CI), 50\% proportion, and 5\% Margin of error.

$$
\mathrm{n}=\frac{(\mathrm{Za} / 2) 2 \times(1-\mathrm{P})}{(\mathrm{W}) 2}
$$

Where,

$\mathrm{n}=$ initial sample size

$\mathrm{Z}=1.96$, the corresponding $\mathrm{Z}$ - score for the $95 \% \mathrm{CI}$

$$
\begin{aligned}
& \mathrm{P}=\text { Proportion }=50 \% \\
& \mathrm{~W}=\text { Margin of error }=5 \%=0.05 \\
& \mathrm{n}=\frac{(1.96) 2 \times 0.5(1-0.5)}{(0.05) 2}=384
\end{aligned}
$$

By considering a $10 \%$ non-response rate and 1.5 design effect, the final sample size for each site was 635. Finally, 
1270 study participants were selected by using a systematic random sampling technique.

From the University of Gondar Comprehensive Specialized Hospital, 40 children have visited the outpatient department every day on average 40 children/day= $1200 /$ month $=3600 / 3$ months. Every day, 8 study participants' information was collected. $K^{\text {th }}=$ Total visited per day $/$ sample size per day $=40 / 8=5$. Therefore, the study participant was selected every 5th child from the daily visited children. Similarly, in Felege Hiwot referral hospital, on average 36 children visit the hospital daily = $1080 /$ month $=3240 / 3$ month, $32 / 8=4$. Therefore, every 4th patient was selected from the daily visited children until the required sample size reached (Fig. 1).

\section{Data collection tools and procedures}

Data regarding the socio-demographic characteristics of children and their caregivers and related characteristics were collected through face-to-face interviews of the caregivers/children using a structured questionnaire adapted from different literature. The data were collected by 4 BSc nurses and strictly followed by 2 supervisors to the overall data collection process from two study sites. A one-day training was given to the data collectors and supervisors about the purpose of the study, data collection tools, collection techniques, and ethical issues during the selection of study participants and collection of the data. All answers to closed-and openended questions were written manually by the interviewer. The supervisors were assessing the consistency and completeness of data on daily basis.

For those children suspected of cancer was sent to pathology, laboratory, and imagining investigations for screening. Different diagnostic procedures were done according to the standard operation procedures of each suspected cases including Complete Blood Count and Peripheral Morphology examination, urine test, ophthalmic examination, ultrasound, magnetic resonance imaging, X-ray on the affected site, and biopsy and/or aspiration from the diseased gland or tissue based on the type and site of the cancer suspected. Their chart numbers, phone number, and follow-up time was taken and followed to make sure the final diagnosis status. Based on the aforementioned information, their pathology, laboratory, and imagining results were confirmed and collected.

\section{Study variables \\ Dependent variable}

Prevalence of childhood cancer.

\section{Independent variables}

Socio-demographic characteristics of children and the caregivers, clinical presentation related characteristics of the children and, feeding and lifestyle-related characteristics.

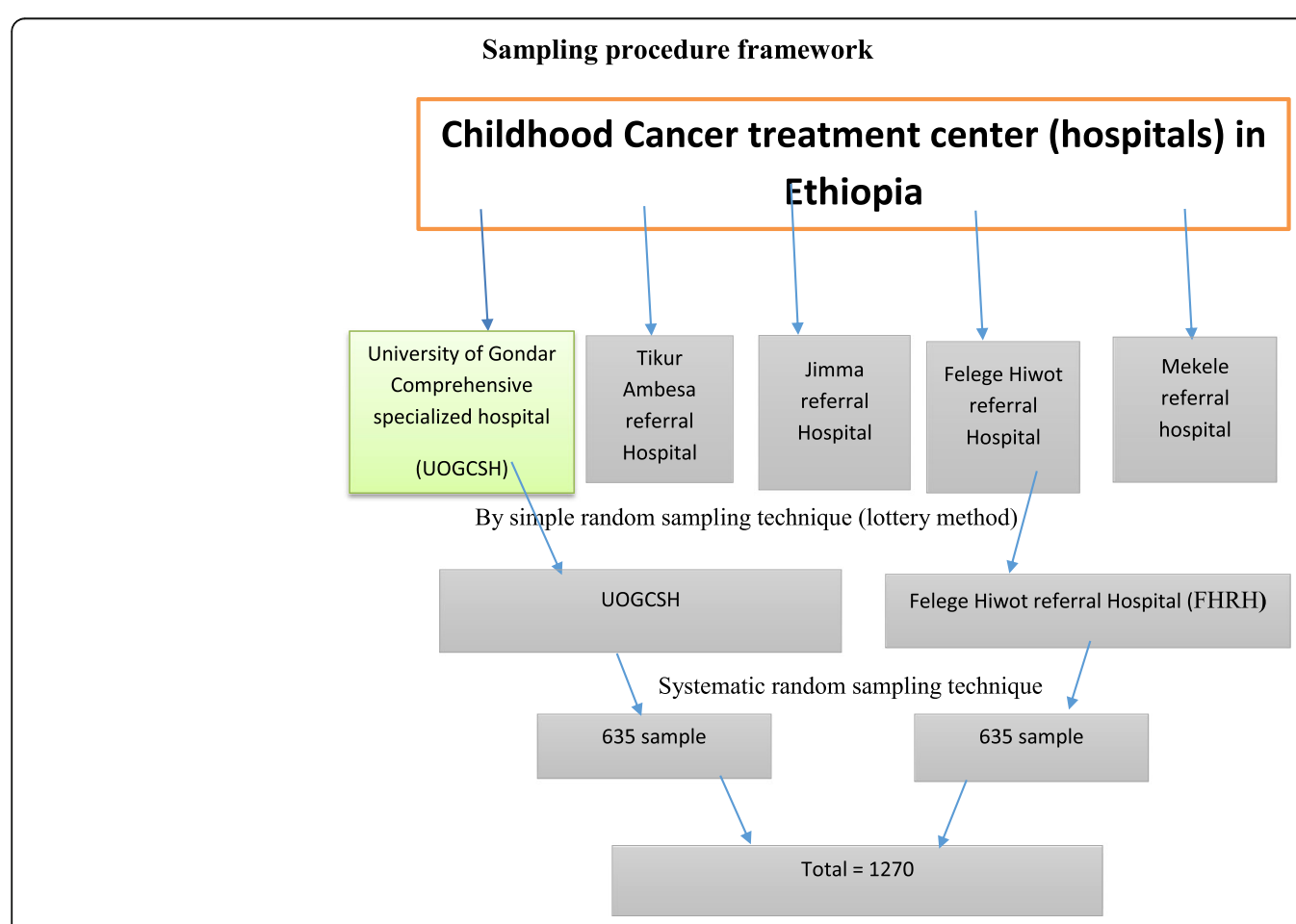

Fig. 1 Sample selection procedure 


\section{Statistical analysis}

The data entry was performed using the statistical program Epi-info version 7 and then, exported into SPSS version 20 for analysis. Descriptive statistics were carried out and presented with narration, tabulation, and graphical presentation. We checked model fitness for the advanced statistical methods, but difficult to proceed with logistical regression model to see the association between dependent and explanatory variables because of the unmet $\mathrm{x}^{2}$ assumption and model fitness.

\section{Quality assurance mechanisms}

To assure the quality of the data, the tool was prepared first in English and then, translated to the national language (Amharic) by language experts in English and Amharic. Data collectors and supervisors were trained on the data collection process for 1 day. The pretest was conducted from $5 \%$ of the total sample size in hospitals which is not selected for actual data collection. Appropriate modifications were made to the tool accordingly. Data collection was closely monitored by investigators and supervisors. Moreover, the data quality was assured by using statistical parameters for assessing the validity of the collected data.

\section{Ethical considerations}

Ethical clearance was issued by the University of Gondar institutional ethical review board. Throughout the data collection, any harm was avoided to the study participants. Respecting the dignity of the study participant had been prioritized. The voluntary participation of respondents was considered. Moreover, participants had the right to withdraw from the study at any stage if they wish to do so. For all study participants, informed consent was obtained from the parent/legal guardian. In addition, assent also obtained from children as appropriate according to their age. In this study, all methods were performed in accordance with the Declaration of Helsinki.

\section{Results}

\section{Sociodemographic characteristics of children and caregiver}

From the total 1270 study participants, 1257 motherchild pairs were included in the final analysis provided that a $98.97 \%$ response rate. The minimum and maximum age of children was 1 month and 179 months with the mean of $32.4(\mathrm{SD}=46.2)$ months, respectively. The minimum and maximum age of the caregiver was 16 years and 61 years with the mean of $32.4 \quad(\mathrm{SD}=6.8)$ years, respectively. The minimum and maximum income of caregivers per month was 0.0 Ethiopian Birr (ETB) and 9000 ETB with the mean of 2022.7 ETB (SD = 1994.3), respectively. Regarding the marital status of the caregiver, most (93\%) were married and 71\% were urban residence. Female caregivers were the dominant $(82.2 \%)$ and more than half (56.4\%) were male children (Table 1 ).

\section{Feeding and lifestyle-related characteristics of children's families}

Almost all (98.2\%) of the children are from non-smoker family and $61.3 \%$ did not frequently consume hot foods and drinks. Most (93.4\%) of the families did not frequently eat red raw meat. About 75.9 and $75.5 \%$ of the family members did not frequently consume fabricated food and not utilized herbicides/pesticides, respectively (Table 2).

\section{Clinical presentation of the children}

From the total children included in this study, 28.24\% presented in the hospital with chief complain of cough or difficulty of breathing followed by fever (13.44\%) and diarrhea (10.82\%) (Table 3).

\section{Prevalence of cancer among children}

From the total 1257 mother-child pair participants, $32(2.5 \%)$ children screened for cancer. Regarding the cancer status of the child, $10(0.8 \%)$ children were diagnosed with different types of childhood cancer (Fig. 2). Two Acute Lymphocytic Leukemia (ALL), two Wilms tumor, two Hodgkin lymphoma, one non-Hodgkin lymphoma, one Parotid cancer, one Retinoblastoma, and one male Breast cancer were reported in the study period from the two study settings (Figure-2).

\section{Distribution of cancer across variables}

The prevalence of childhood cancer was 0.9 and $0.7 \%$ among male and female children, respectively. Six out of 10 were from urban residence families and regarding parents' occupation, 3 from merchant and 4 were from a farmer family. Six of them were in the age group from15 years. All cancer positive children were from married caregivers (Table 4).

\section{Discussion}

Despite an increasing burden, childhood cancer was poorly quantified and continues to receive low public health priority in Ethiopia, largely because of the overwhelming burden of communicable diseases and limited resources. Hence, we aimed to determine the prevalence of childhood cancer and predictors among mother-child pairs in two referral hospitals in Ethiopia. In this study, the prevalence of childhood cancer was $0.8 \%$ (95\%, CI: 0.3-1.3). This finding is a bit lower than studies conducted in Africa that ranged between $1.4 \%$ in Ghana to $10.0 \%$ in Rwanda [21], and 1.6 to $4.8 \%$ in India [22]. The discrepancy might be due to differences in the diagnostic capacity of the health institutions or availability of 
Table 1 Socio-demographic-related variables of children and caregivers attending clinic at FHRH and UOGCSH, Northwest Ethiopia in 2019

\begin{tabular}{l} 
Variables \\
\hline Age of the child in year \\
$\quad<1$ year \\
$1-5$ year \\
$5-10$ year \\
$\geq 10$ year
\end{tabular}

Frequency $(n=1257)$

Percentage (\%)

Sex of the child

Male

Female

Rural

Residence of the child

Urban

Age of caregiver in years

15-25 year

26-35 year

708

36-45 year

$>45$ year

Sex of care giver

Male

Female

Region of caregiver

Amhara

Tigray

Oromia

Others

Religion of caregiver

Orthodox

Muslim

118

9.4

Protestant

Others

Marital status of caregiver

Single

Married

Others

Educational status of care giver

Illiterate

Primary school

Secondary school

College/University

Occupation of the caregiver

Not employed

Government employed

Farmer 
Table 1 Socio-demographic-related variables of children and caregivers attending clinic at FHRH and UOGCSH, Northwest Ethiopia in 2019 (Continued)

\begin{tabular}{lll}
\hline Variables & Frequency $(\boldsymbol{n}=\mathbf{1 2 5 7})$ & Percentage $(\%)$ \\
\hline Daily Laborer & 39 & 3.1 \\
Housewife & 339 & 27.0 \\
Monthly income (ETB) & & 24.2 \\
No regular monthly income & 304 & 20 \\
Less than 1000 & 252 & 29.1 \\
1000-3000 & 366 & 20.7 \\
$3001-5000$ & 260 & 6.0 \\
$5001-10,000$ & 75 & \\
\hline
\end{tabular}

diagnostic facilities, health-seeking behavior/norms of the population, and perhaps access to health services. For instance, only $23 \%$ of health facilities offer services for cancer in Ethiopia [23]. Accurate epidemiological data on pediatric cancers will enable the mobilization of sufficient resources for proper screening, prevention, and treatment of cancers. Most of the children with cancer in our analysis resided in the urban area of the study setting due to the proximity and its accessibility of medical resources. But a child from a rural area might have died before registration or diagnosis as access to health care is very deficient. Hence, improved diagnostics and suspicion on the clinical examination might result in an increasing number of patients diagnosed with cancer in rural areas. The WHO global initiative for childhood cancer aimed to increase the overall survival for six key

Table 2 Feeding and lifestyle of related-variables of children's families attend clinic at FHRH and UOGCSH, Northwest Ethiopia in 2019

\begin{tabular}{lll}
\hline Variables & Frequency $(\boldsymbol{n}=\mathbf{1 2 5 7})$ & Percentage (\%) \\
\hline $\begin{array}{l}\text { Smoker family } \\
\text { Nomber }\end{array}$ & 1235 & 98.2 \\
Yes & 22 & 1.8 \\
Frequent consumption of hot foods and drinks & \\
No & 771 & 61.3 \\
Yes & 486 & 48.7 \\
Frequent consumption of red raw meat & \\
No & 1174 & 93.4 \\
Yes & 83 & 6.6 \\
Frequent consumption of fabricated food & \\
No $\quad 954$ & 75.9 \\
Yes & 303 & 24.1 \\
Using herbicides or pesticides & \\
No & 949 & 75.5 \\
Yes & 308 & 24.5 \\
\hline
\end{tabular}

childhood cancers (acute lymphoblastic leukemia, Burkitt's lymphoma, Hodgkin lymphoma, low-grade glioma, retinoblastoma, and Wilms tumor) to $60 \%$ globally by 2030 through the development of national centers of excellence and expanding regional satellites [24]. Moreover, in low- and middle-income countries, the survival of children is highly dependent on several health indicators, including the number of physicians and nurses per 1000 population, infrastructure, human resources, and level of supportive care [25]. However, from more than 46 hospitals in Amhara regional state only two centers were found who had pediatric-specific cancer center which makes very difficult in the accessibility of early diagnosis and treatment. This will have ended with poor survival for children with childhood cancer in resourcelimited countries like Ethiopia.

In this study, males were more affected than female children. The finding was supported with previous studies, risk factors for childhood cancer including demographic, environmental, intrinsic, and genetic factors [20, $22,26]$. On sociodemographic factors for most childhood cancers, there is a slight male preponderance as reported in the previous studies [13, 20, 22] but equal distribution was observed in this study. Again, in this study, more than half of the child cancer were occurred in the age group from 1 to 5 years in a similar manner from the childhood cancer age groups, from 0 to 4-years age group had the greatest contribution in Australia [27] and to global childhood cancer analysis [24].

Concerning distribution, two ALL, two Wilms tumor, two Hodgkin lymphomas were reported in this study. Similarly, the most common childhood cancer is leukemia in India [22] and Australia [27]. In other studies, leukemia and retinoblastomas in Namibia [28], leukemia and lymphomas in central Sudan [29], Burkitt lymphoma, retinoblastoma, and Wilms tumor in Northwest Cameroon [30] were reported. In Western Africa, Non-Hodgkin lymphoma was the most common in Ghana, in Ivory Coast and Mali [21]. Furthermore, in eastern Africa, Uganda recorded Kaposi sarcoma (KS) as 
Table 3 Children's clinical characteristics attending clinic at FHRH and UOGCSH, Northwest Ethiopia in 2019

\begin{tabular}{lll}
\hline Variables & Frequency $(\boldsymbol{n}=\mathbf{1 2 5 7})$ & Percentage (\%) \\
\hline Chief complain $(\boldsymbol{n}=\mathbf{1 2 5 7})^{*}$ & & 5.65 \\
Vomiting & 71 & 10.82 \\
Diarrhea & 136 & 13.44 \\
Fever & 169 & 28.24 \\
Cough/Difficulty of breathing & 355 & 5.41 \\
Abdominal distention (pain) & 68 & 3.18 \\
Swelling & 40 & 3,26 \\
Itching/rash & 41 & 1.11 \\
Ear problem/pain/discharge & 14 & 1.51 \\
Difficulty of swallowing & 19 & 1.35 \\
Loss of appetite & 17 & 0.875 \\
Chest pain & 11 & 2.23 \\
Fatigue & 28 & 5.09 \\
Eye problem & 64 & 1.67 \\
Pain/burning sensation during urination & 21 & 16.95 \\
Other** & 213 & \\
\hline
\end{tabular}

${ }^{*}$ A child may have more than one chief complain, ${ }^{* *}$ those chief complains having less than 11 frequency were merged as others

the most common tumor in children while two Kenyan centers reported mainly Burkitt lymphoma (BL) [31] and lymphomas, Wilms tumor, and retinoblastoma in North-West Ethiopia [32]. The difference would be due to variation in genetic makeup and environmental risk factor.

Children with cancer in Sub-Saharan Africa face paramount challenges as children with cancer in low-income countries often present with advanced-stage disease, lack of health care facilities, transportation, information about the disease, and treatment options [33]. In a similar manner in Ethiopia, apart from this finding, a previous study also revealed that children with cancer were exposed to prolonged hospitalization due to a lack of anti-cancer drugs, adequate diagnostic and treatment facilities [13]. As strength the study figures out the epidemiology of childhood cancer in the study setting. The other strength of this study, it will serve as baseline for further study on the area and informative for health works and other stockholders in the area. As limitation the study was institution based among children who visit the OPD for different illness which may not representative for the children who is apparently healthy and may have cancer in the community. The limitation was due feasibility issue in terms of resource.

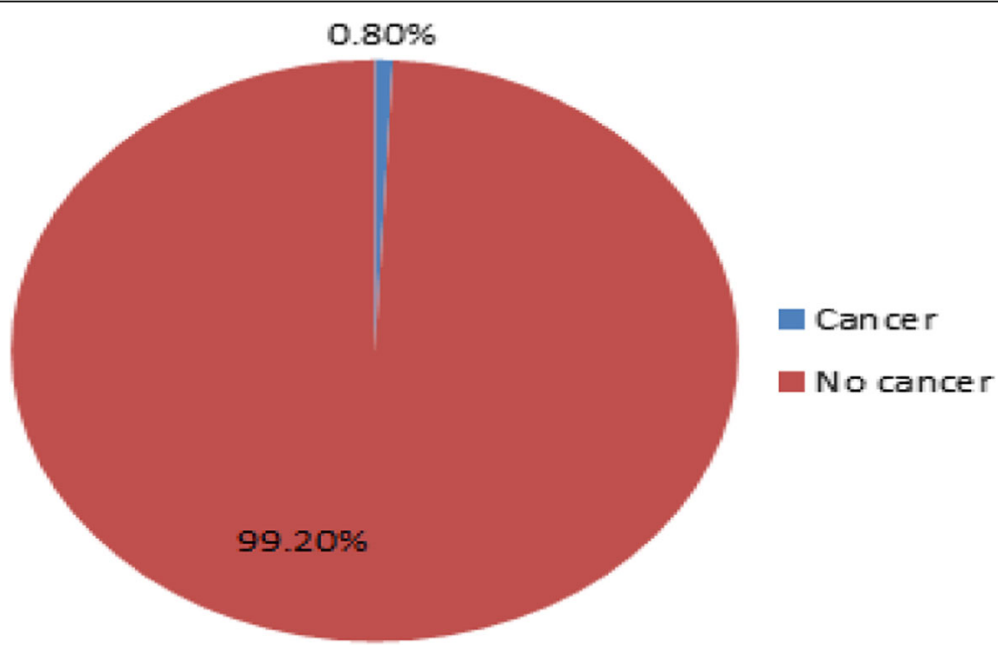

Fig. 2 Pie chart presentation of cancer prevalence 
Table 4 Prevalence of childhood cancer among children attending clinic at FHRH and UOGCSH, Northwest Ethiopia in 2019

Variables
Sex of the child
Male
Female
Residence
Urban
Rural
Age of the child
Less than 1 year
$1-5$ year
$5-10$ year
10 year and above

\section{Cross-tabulation $(n=1257)$}

\section{Cancer}

No cancer

5

Age of the care giver

15-25 year

26-35 year

36-45 year

Above 45 year

$$
1
$$

Sex of the caregiver

$$
\begin{aligned}
& \text { Male } \\
& \text { Female }
\end{aligned}
$$

Educational status of care giver

|lliterate

Primary school

Secondary school

College/University

\section{Occupation}

Not employed
Government employed
Farmer
Merchant
Daily Laborer
Housewife

Monthly income (ETB)

No regular monthly income

Less than 1000

1000-3000

3001-5000

5001-10,000

Religion of caregiver

Orthodox

Muslim

Protestant

4

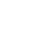

(1)

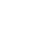

3




\section{Conclusions}

Although childhood cancers receive little attention from local policymakers, the prevalence of childhood cancer remains prevalent in the study setting. Meanwhile, an increased number of reported cases might occur with the increase in awareness, knowledge, diagnostic tools, and affordability. Therefore, large-scale community-based study shall be conducted to address those children who did not gate the access.

\section{Abbreviation \\ ALL: Acute Lymphocytic Leukemia; ETB: Ethiopian Birr; FHRH: Felege Hiwot Referral Hospital; Km: Kilometers; NCD: Non-communicable Diseases; OPD: Outpatient Department; UOGCSH: University of Gondar Comprehensive Specialized Hospital; USA: United State of America; WHO: World Health Organization}

\section{Acknowledgments}

The authors acknowledge the University of Gondar.

\section{Availability of data and material}

Data generated/ analyzed during this study are included in the manuscript.

\section{Authors' contributions}

$A E$, NTA, AW, GMB, YB, and CAW conceived and designed the study and preparing the manuscript. TAA, AAM, EGZ, AT, MAT, and SFK review and provide constructive feedback in the designing phase of the study, involved in the analysis, and review the manuscript. All authors involved in write, review and approve the final draft of the manuscript. All the authors read the manuscript before submitting it to a journal for publication. The authors read and approved the final manuscript.

\section{Funding}

This study was funded by the University of Gondar. However, the funder had no role in the data collection, analysis and preparation of the manuscript, and publication decision.

\section{Declarations}

\section{Ethics approval and consent for participation}

Ethical clearance was obtained from the University of Gondar ethical review committee. For all study participants, informed consent was obtained from the parent/legal guardian. Besides assent is also obtained from children as appropriate according to their age. In this study all methods were performed in accordance with the Declaration of Helsinki.

\section{Consent for publication}

Not applicable.

\section{Competing interests}

The authors declared no competing interests.

\section{Author details}

${ }^{1}$ Department of Pediatrics and Child Health Nursing, School of Health Sciences, College of Medicine and Health Sciences, Bahir Dar University, Bahir Dar, Ethiopia. ${ }^{2}$ Department of Pediatrics and Child Health Nursing, School of Nursing, College of Medicine and Health Sciences, University of Gondar, P.O.BOX 196, Gondar, Ethiopia. ${ }^{3}$ Department of Epidemiology and Biostatistics, Institute of Public Health, College of Medicine and Health Sciences, University of Gondar, Gondar, Ethiopia. ${ }^{4}$ Department of Surgical Nursing, School of Nursing, College of Medicine and Health Sciences, University of Gondar, Gondar, Ethiopia. ${ }^{5}$ Department of Pediatrics and Child Health, School Medicine, College of Medicine and Health Sciences, University of Gondar, Gondar, Ethiopia.
Received: 7 December 2020 Accepted: 2 March 2021

Published online: 12 March 2021

\section{References}

1. Vineis P. Definition and classification of cancer: monothetic or polythetic? Theor Med. 1993;14(3):249-56.

2. de Fine LS, Rugbjerg K, Gudmundsdottir T, Bonnesen TG, Asdahl PH, Holmqvist AS, Madanat-Harjuoja L, Tryggvadottir L, Wesenberg F, Hasle H. Long-term inpatient disease burden in the adult life after childhood Cancer in Scandinavia (ALiCCS) study: a cohort study of 21,297 childhood cancer survivors. PLoS Med. 2017:14(5):e1002296.

3. Gupta S, Rivera-Luna R, Ribeiro RC, Howard SC. Pediatric oncology as the next global child health priority: the need for national childhood cancer strategies in low-and middle-income countries. PLoS Med. 2014;11(6): e1001656.

4. Parkin M. Childhood cancer in developing countries: environmental factors. Int J Pediatr Hematol Oncol. 1995;2(5):411-7.

5. World Health Organization: International childhood cancer day; 2015.

6. Kingham TP, Alatise OI, Vanderpuye V, Casper C, Abantanga FA, Kamara TB, Olopade Ol, Habeebu M, Abdulkareem FB, Denny L. Treatment of cancer in sub-Saharan Africa. Lancet Oncol. 2013;14(4):e158-67.

7. Steliarova-Foucher E, Colombet M, Ries LA, Moreno F, Dolya A, Bray F, Hesseling P, Shin HY, Stiller CA, Bouzbid S. International incidence of childhood cancer, 2001-10: a population-based registry study. Lancet Oncol. 2017;18(6):719-31.

8. White Y, Castle VP, Haig A. Pediatric oncology in developing countries: challenges and solutions. J Pediatr. 2013;162(6):1090-1091. e1091.

9. Ward E, DeSantis C, Robbins A, Kohler B, Jemal A. Childhood and adolescent cancer statistics, 2014. CA Cancer J Clin. 2014;64(2):83-103.

10. Youlden DR, Baade PD, Green AC, Valery PC, Moore AS, Aitken JF. The incidence of childhood cancer in Australia, 1983-2015, and projections to 2035. Med J Aust. 2020;212(3):113-20.

11. Ba-Saddik IA. Childhood cancer in Aden, Yemen. Cancer Epidemiol. 2013; 37(6):803-6.

12. Federal Ministry of Health Ethiopia. National Cancer Control Plan 2016-2020 of Ethiopia. Prev Control Dir. 2015;2015(10):83.

13. Yifru S, Muluye D. Childhood cancer in Gondar university hospital, Northwest Ethiopia. BMC Res Notes. 2015;8(1):474.

14. Travasso C. Indian health ministry told to develop a framework for cancer screening. London: British Medical Journal Publishing Group; 2016.

15. Elnuweiry HA, Abed Y. Risk factors for paediatric cancer in the Gaza strip: a case-control study. Lancet. 2018;391:S13.

16. Hawkins M, Wilson L, Stovall M, Marsden H, Potok M, Kingston J, Chessells J. Epipodophyllotoxins, alkylating agents, and radiation and risk of secondary leukaemia after childhood cancer. Br Med J. 1992;304(6832):951-8.

17. Cardis E, Hatch M. The Chernobyl accident-an epidemiological perspective. Clin Oncol. 2011;23(4):251-60.

18. Linet MS, Pyo Kim K, Rajaraman P. Children's exposure to diagnostic medical radiation and cancer risk: epidemiologic and dosimetric considerations. Pediatr Radiol. 2009:39(1):4-26.

19. Hsu W-L, Preston DL, Soda M, Sugiyama H, Funamoto S, Kodama K, Kimura A, Kamada N, Dohy H, Tomonaga M. The incidence of leukemia, lymphoma and multiple myeloma among atomic bomb survivors: 1950-2001. Radiat Res. 2013;179(3):361-82.

20. Spector LG, Pankratz N, Marcotte EL. Genetic and nongenetic risk factors for childhood cancer. Pediatr Clin. 2015;62(1):11-25.

21. Stefan DC. Patterns of distribution of childhood cancer in Africa. J Trop Pediatr. 2015;61(3):165-73.

22. Arora R, Eden T, Kapoor G. Epidemiology of childhood cancer in India. Indian J Cancer. 2009:46(4):264

23. Gelibo T, Getachew T, Bekele A, Defar A, Amenu K, Taddesse M, Teklie H, Assefa $Y$, Kebede A. Availability and readiness of services for cancer care at health facilities in Ethiopia: implication for action. Ethiop J Health Dev. 2017; 31(1):391-6

24. Force LM, Abdollahpour I, Advani SM, Agius D, Ahmadian E, Alahdab F, Alam T, Alebel A, Alipour V, Allen CA. The global burden of childhood and adolescent cancer in 2017: an analysis of the global burden of disease study 2017. Lancet Oncol. 2019;20(9):1211-25.

25. Rodriguez-Galindo C, Friedrich P, Alcasabas P, Antillon F, Banavali S, Castillo $L$, Israels T, Jeha S, Harif M, Sullivan MJ, et al. Toward the cure of all children 
with Cancer through collaborative efforts: pediatric oncology as a global challenge. J Clin Oncol. 2015;33(27):3065-73.

26. FMOH: National Cancer Control Plan. 2015

27. Baade P, Youlden D, Valery P, Hassall T, Ward L, Green A, Aitken J. Trends in incidence of childhood cancer in Australia, 1983-2006. Br J Cancer. 2010; 102(3):620-6.

28. Stefan DC, Baadjes B, Kruger M. Incidence of childhood cancer in Namibia: the need for registries in Africa. Pan Afr Med J. 2014;17.

29. Elhassan MM, Mohamedani AA, Yousif NO, Elhaj NM, Qaddoumi I, Abuidres DO. Epidemiological review of childhood cancers in Central Sudan. SA J Oncol. 2018;2(1):1-7.

30. Borah R, Kouya FT. Epidemiology of pediatric cancer in the Northwest Region of Cameroon. medRxiv. 2020.

31. Kruger M, Hendricks $M$, Davidson A, Stefan CD, van Eyssen AL, Uys R, van Zyl A, Hesseling P. Childhood cancer in Africa. Pediatr Blood Cancer. 2014; 61(4):587-92.

32. Tefera B, Assefa M, Abebe B, Rauch D. Patterns of Cancer in University of Gondar Hospital: north-West Ethiopia. J Oncol Med Pract. 2016;1 (106):2.

33. Israëls T. Aspects of the management of children with cancer in Malawi, vol. 51; 2008.

\section{Publisher's Note}

Springer Nature remains neutral with regard to jurisdictional claims in published maps and institutional affiliations.

Ready to submit your research? Choose BMC and benefit from:

- fast, convenient online submission

- thorough peer review by experienced researchers in your field

- rapid publication on acceptance

- support for research data, including large and complex data types

- gold Open Access which fosters wider collaboration and increased citations

- maximum visibility for your research: over $100 \mathrm{M}$ website views per year

At BMC, research is always in progress.

Learn more biomedcentral.com/submissions 